\title{
RELATIONSHIP BETWEEN PSYCHOSOCIAL ADJUSTMENT AND PERCEPTION OF MATERNAL ATTITUDES ${ }^{1}$
}

\author{
LENORE BEHAR 2 AND ROGER F. SPENCER
}

University of North Carolina

\begin{abstract}
A sample of 26 adult male hemophiliacs was divided into two groups on the basis of their psychosocial adjustment. The poorly adjusted group rated their mothers as significantly higher in tendencies toward dominating, overprotecting, and ignoring their children.
\end{abstract}

In studying the psychosocial adjustment of hemophiliacs, it was observed that these $S$ s frequently were exposed to similar patterns of child rearing. Support was found in earlier studies (Agle, 1964; Browne, Mally, \& Kane, 1960) that mothers of hemophiliacs tend to overprotect and infantilize their sons. In fact, studies of juvenile diabetics (Swift, Seidman, \& Stein, 1967) and of other children considered to be physically vulnerable (Green \& Solnit, 1964) also revealed the mothers' tendencies to protect, infantilize, and dominate their children. These attitudes seemed initially based on the realistic possibility of physical danger to the child; however, even when the children in these studies were old enough to fend for themselves, the mothers continued their protective roles.

The mothers' attitudes in these studies seemed to reflect feelings of inadequacy as a childbearer and guilty feelings of having burdened a child with a chronic illness. Although feelings of guilt and responsibility were also apparent in mothers of diabetics and other chronically ill children, they may be more salient in mothers of hemophiliacs, for in this disease the defects in blood clotting are transmitted as sex-linked, recessive genetic traits by the carrier mother to the son. That is, the mother passes on a genetically determined condition which she herself does not have.

Hemophilia is a life-long, serious condition, found almost exclusively in males and usually

I The study was supported by Medical School Grant 324 UNI-1-218 from the University of North Carolina.

2 Requests for reprints should be sent to Lenore Behar, Department of Psychiatry, University of North Carolina Medical School, Chapel Hill, North Carolina 27514. discovered in infancy or early childhood. It is characterized by the persistence of bleeding following an injury or by "spontaneous" bleeding into joints and soft tissues (Ratnoff, 1963). Although modern medical methods of handling bleeding episodes have decreased the mortality considerably, serious problems still occur-most frequently crippling of joints. In order to avoid the danger of bleeding, it may be necessary for a mother to restrict her son's physical activity, and in many situations to inhibit aggressive behavior. Having experienced these restrictions of childhood activity, coupled with frequent periods of being confined to bed and waited on, many adult hemophiliacs tend to have strong passive dependent tendencies (Agle, 1964; Browne, Mally, \& Kane, 1960). Mattsson and Gross (1966) have found that the levels of adjustment achieved are closely related to childrearing attitudes and anxiety in the mother.

Further investigation of the mother-child relationship should be fruitful in understanding the level of social adjustment achieved by adult hemophiliacs. Dealing with the adult patient offers the advantage of more crystallized personality characteristics. Understanding how he perceives his mother now and how he perceives her child-rearing techniques in retrospect should yield clues pertaining to social adjustment.

\section{METHoD}

In the present study, 26 male $S$ s were divided into two groups on the basis of their psychosocial adjustment, which was measured by the Social Maturity Index of the California Personality Inventory (Gough, 1966). The scores were divided at the median, yielding $14 S$ s rated as having low social maturity and 12 as having high social maturity. In this sample the range of scores was 40-58, with a median of 47 . The mean of the low group was 45.57 
TABLE 1

Description OF THE SUbject Groups

\begin{tabular}{|c|c|c|}
\hline \multirow{2}{*}{ Item } & \multicolumn{2}{|c|}{ Group } \\
\hline & $\begin{array}{l}\text { High social maturity } \\
\qquad(n=12)\end{array}$ & $\begin{array}{l}\text { Low social maturity } \\
\qquad(n=14)\end{array}$ \\
\hline Age & $\begin{array}{l}M=29.0 \\
\quad \text { (range } 16-75 \text { ) }\end{array}$ & $\begin{array}{l}M=32.9 \\
\quad \text { (range } 17-67 \text { ) }\end{array}$ \\
\hline $\begin{array}{l}\text { Social class } \\
\text { Education } \\
\text { Severity of } \\
\quad \text { illness }\end{array}$ & $\begin{array}{c}M=3.5 \\
M=12 \text { th grade } \\
4 \text { mild } \\
8 \text { severe }\end{array}$ & $\begin{array}{c}M=4.0 \\
M=10 \text { th grade } \\
5 \text { mild } \\
9 \text { severe }\end{array}$ \\
\hline
\end{tabular}

- Measured on a 5-point scale, with 1 representing the highest class (Hollingshead \& Redlich, 1958).

and that of the high group, 53.16, the difference being statistically significant beyond the .001 level $(t=8.56)$. In other respects, the two groups were rather equally matched, as seen in Table 1.

The $S$ s in both groups were administered the Mark Scale (Harris, 1955), a scale designed to measure $S$ 's perception of his mother's child-rearing attitudes. The scale consists of 52 items, items which were rated by a panel of experts to reflect dominating, overprotecting, and ignoring on the part of the person being rated-in this case the mother and the ideal mother. On this test, $S$ is asked whether his mother would agree or disagree with the following types of statements:

A mother should never be separated from her child.

If a child is quiet for a few minutes, a mother should immediately find out what he's thinking.

\section{Results and Discussion}

Table 2 shows the differences between the two groups on this questionnaire. The highsocial-maturity group consistently rate the

\section{TABLE 2}

Perception of Maternat Attitudes: Mean Numbers of Items Indicating Negative Child-Rearing Practices

\begin{tabular}{l|r|r|c}
\hline \multirow{2}{*}{ Rating of } & \multicolumn{2}{|c|}{ Group } & \\
\cline { 2 - 3 } & $\begin{array}{c}\text { High } \\
\text { social } \\
\text { maturity } \\
(n=12)\end{array}$ & $\begin{array}{c}\text { Low } \\
\text { social } \\
\text { maturity } \\
(n=14)\end{array}$ & $t$ \\
\cline { 2 - 4 } & & & \\
\hline Real mother & 7.08 & 9.64 & $3.01^{*}$ \\
Dominance (15 items) & 3.83 & 6.36 & $3.18^{*}$ \\
Ignoring (13 items) & \\
Overprotecting (24 items) & 5.91 & 9.26 & $2.66^{*}$ \\
Ideal mother & & & \\
Dominance (15 items) & 5.58 & 9.71 & $3.97^{* *}$ \\
Ignoring (13 items) & 3.67 & 6.07 & $2.97^{*}$ \\
Overprotecting (24 items) & 5.83 & 10.86 & $2.57^{*}$ \\
\hline
\end{tabular}

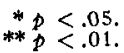

mother as less dominating, ignoring, and overprotecting than the low-social-maturity $S$ s did. The more mature $S$ s rated their mothers as better mothers, or at least as mothers lower in these three negative characteristics. Interesting, too, is the direction of change in rating the ideal mother, who was described to $S$ s in the instructions as "the best mother possible." The more socially mature $S$ s rated the ideal mother even lower than the real mother. The less socially mature $S$ s rate the ideal mother even higher on these negative characteristics, especially on the dimension of overprotection. One might infer the statement, "My mother was quite overprotecting but an ideal mother should be even more so" by the less mature $S$. We feel that the ideal mother represents fantasied wish fulfillment and that these individuals would have wanted even more overprotection and domination than their mothers provided. Support for this interpretation is gained from previous work with this same $S$ group by Spencer (1968), in which he found that many of the less welladjusted patients have had serious marital problems or have been unable to cut dependent ties with their mothers, some have developed hostile-dependent relationships with their wives, and some have had continued problems with alcoholism-all reflecting in one way or another a passive dependent orientation with a wish to be dominated and protected.

The present study does not indicate whether a person is less well adjusted because he has been raised by a dominating and overprotective mother or whether he just sees his relationship with his mother in this way because he is poorly adjusted. However, the previously mentioned studies of hemophiliacs lend considerable support to the former interpretation, that a dominating and overprotective mother tends to produce the type of adult described above-passive and dependent. If so, preventive work is necessary. Certainly, the mother-child relationship in the case of genetically determined conditions or chronic childhood disorders has more of a chance of being problematic than when the child is normal. At least in these trouble-prone cases, early counseling with the mothers or 
with both parents could be offered in an attempt to alleviate feelings of guilt and to thwart the development of an overprotective relationship.

\section{REFERENCES}

AgLE, D. P. Psychiatric studies of patients with hemophilia and related states. Archives of Internal Medicine, 1964, 114, 76-82.

Browne, J. W., Mally, M. A., \& Kane, R. P. Psychosocial aspects of hemophilic children and their families. American Journal of Orthopsychiatry, $1960,30,730-740$.

Green, M., \& Solnit, A. J. Reactions to the threatened loss of a child: A vulnerable child syndrome. Pediatrics, 1964, 34, 58-66.

Gougr, H. G. Appraisal of social maturity by means of the CPI. Journal of Abnormal Psychology, 1966, 71, 189-195.
HARRIs, J. G. A study of the mother-son relationship in schizophrenia. Unpublished doctoral dissertation, Duke University, 1955.

Hollingshead, A. B., \& ReDlich, F. C. Social class and mental illness. New York: Wiley, 1958.

Mattsson, A., \& Gross, S. Social and behavioral studies on hemophilic children and their families. Journal of Pediatrics, 1966, 68, 952-964.

Ratnoff, O. D. The therapy of hereditary disorders of blood coagulation. Archives of Internal Medicine, 1963, 112, 92-111.

SPENCER, R. F. Incidence of social and psychiatric problems in a group of hemophiliac patients. North Carolina Medical Journal, 1968, 29, 332335.

SwIFT, C. R., Serpman, F., \& Sten, H. Adjustment problems in juvenile diabetes. Psychosomatic Medicine, 1967, 29, 555-571.

(Received May 4, 1968) 